Polymer Journal, Vol. 8, No. 1, pp 53-59 (1976)

\title{
Cationic Polymerization of Phenylbutadienes. II. Initiation Reaction in Cationic Polymerization of Phenylbutadienes Catalyzed by Triphenylmethylstannic Pentachloride
}

\author{
Ryuzo Asami and Kan-ichi Hasegawa \\ Department of Synthetic Chemistry, Nagoya Institute of Technology, \\ Gokiso-cho, Showa-ku, Nagoya 466, Japan.
}

(Received May 30, 1975)

\begin{abstract}
Initiation in cationic polymerization of phenyl-substituted 1,3-butadienes with triphenylmethylstannic pentachloride as catalyst was studied. The rates of consumption of $\mathrm{Ph}_{3} \mathrm{CSnCl}_{5}$ with 1 -phenyl-substituted butadienes are represented by the following equation

$-\mathrm{d}\left[\mathrm{Ph}_{3} \mathrm{CSnCl}_{5}\right] / \mathrm{d} t=k_{\mathrm{i}}{ }^{\prime}\left[\mathrm{Ph}_{3} \mathrm{CSnCl}_{5}\right][\mathrm{M}], \quad$ where $\mathrm{M}$ means monomer.

On the other hand, in the case of 2-phenyl-substituted butadienes the rate is represented as follows

$-\mathrm{d}\left[\mathrm{Ph}_{3} \mathrm{CSnCl}_{5} / \mathrm{d} t=k_{\mathrm{i}}^{\prime}\left[\mathrm{Ph}_{3} \mathrm{CSnCl}_{5}\right][\mathrm{M}]+k\left[\mathrm{Ph}_{3} \mathrm{CSnCl}_{5}\right]\left([\mathrm{M}]_{0}-[\mathrm{M}]\right)\right.$

and the formation of a $\pi$-complex between the monomer and a carbonium ion is suggested. The initiation rate constants decreased according to the following order:

1-phenyl-1,3-butadiene $>2$-phenyl-1,3-butadiene $>1$ 1,1-diphenyl-1,3-butadiene $>$

1,2-diphenyl-1,3-butadiene $>2,3$-diphenyl-1,3-butadiene.

1,4-Diphenyl-1,3-butadiene did not react with $\mathrm{Ph}_{3} \mathrm{CSnCl}_{5}$ at all. The high reactivity of phenylbutadienes toward $\mathrm{Ph}_{3} \mathrm{CSnCl}_{5}$ in comparison with that of vinyl monomers could be ascribed to the stabilization of allyl-type cations which were formed by an attack of a trityl cation onto the 4-position and the 1-position carbon for 1-phenylbutadienes and 2-phenylbutadiene, respectively.

KEY WORDS Triphenylmethylstannic Pentachloride / Initiation /

1-Phenyl-Substituted Butadiene / 2-Phenyl-Substituted Butadiene /

Cationic Polymerization /
\end{abstract}

In a preceding paper, ${ }^{1}$ it has been reported that trans-1-phenyl-1,3-butadiene was a highly reactive monomer in the cationic polymerization. This high reactivity could be explained in terms of the high stability of the cinnamyl-type cation formed. The stabilization of allyl type cations is thought to have a strong effect on the initiation rate in the cationic polymerization of dienes.

As it has been difficult to measure directly the concentration of any propagating species other than the oxonium ion, ${ }^{2}$ only the initiation rate constant of the polymerization by a stable carbonium-ion salt ${ }^{3,4}$ has been determined by UV spectra in the cationic polymerization of vinyl monomers.

In this series, we tried to determine the rates of initiation in polymerizations of phenylbutadienes in order to make clear the relation between the reactivity and the structure of the diene monomers in cationic polymerization. In this paper, the initiation reaction of phenylsubstituted-1,3-butadiene was investigated by use of triphenylmethylstannic pentachlolide as initiator. The mechanism of the initiation reaction of phenylbutadienes will be discussed.

\section{EXPERIMENTAL}

\section{Materials}

trans-1-Phenyl-1,3-butadiene (1-PB) was prepared as in a previous paper. ${ }^{1}$ 2-Phenyl-1,3butadiene was synthesized from the corresponding alcohol prepared according to the method of Marvel, et al., ${ }^{5}$ and the subsequent dehydration by potassium bisulfate: bp $62-65^{\circ} \mathrm{C}(23 \mathrm{~mm})$ [lit. ${ }^{5}$ bp $\left.57-63^{\circ} \mathrm{C}(13 \mathrm{~mm})\right]$. 1,1-Diphenyl-1,3-butadiene (1,1-DPB) was prepared according to the method of Eisch and Husk: ${ }^{6} \mathrm{mp} 38.5-39.0^{\circ} \mathrm{C}$ 
[lit. $\left.{ }^{6} \mathrm{mp} 38-39^{\circ} \mathrm{C}\right]$. trans-1,2-Diphenyl-1,3-butadiene $(1,2-\mathrm{DPB})$ was synthesized according to the method of Alder, et al.: $:^{7} \mathrm{mp} 56.0-56.7^{\circ} \mathrm{C}$ [1it. ${ }^{7} \mathrm{mp} 57^{\circ} \mathrm{C}$ ]. trans, trans-1,4-Diphenyl-1,3butadiene (1,4-DPB) was prepared according to the method of Corson: ${ }^{8} \mathrm{mp} 153.0-155.5^{\circ} \mathrm{C}$ [lit. ${ }^{8}$ $\mathrm{mp} 152.5-153.5^{\circ} \mathrm{C}$ ]. 2,3-Diphenyl-1,3-butadiene (2,3-DPB) was prepared according to the method which involved dehydration of the corresponding pinacohol and purified by recrystallization from methanol: ${ }^{9} \mathrm{mp} 48-49^{\circ} \mathrm{C}$ [1it. ${ }^{\circ} \mathrm{mp} 49-50^{\circ} \mathrm{C}$ ]. The purities of these monomers were more than 99\% according to GLC analysis. Triphenylmethylstannic pentachloride $\left(\mathrm{Ph}_{3} \mathrm{CSnCl}_{5}\right)$ was synthesized as in the preceding paper. ${ }^{1}$ Ethylene dichloride (EDC) was purified in the usual manner. These monomers and the solvent were further purified on a vacuum line with calcium hydride to take off the last trace of water, and finally distilled into ampoules with a break-seal.

\section{Procedures}

Polymerization was carried out under high vacuum conditions, with air pressure of $c a \cdot 10^{-5}$ $\mathrm{mmHg}$. The initiation reaction was performed in a quartz cell with a $0.2-\mathrm{cm}$ light path as shown in Figure 1. The rate of consumption of $\mathrm{Ph}_{3} \mathrm{CSnCl}_{5}$ by the reaction with phenylbutadienes was measured from the absorbance at $430 \mathrm{~nm}$ on a Hitachi 124 Spectrophotometer in a thermostat bath. For calculation of the concentration

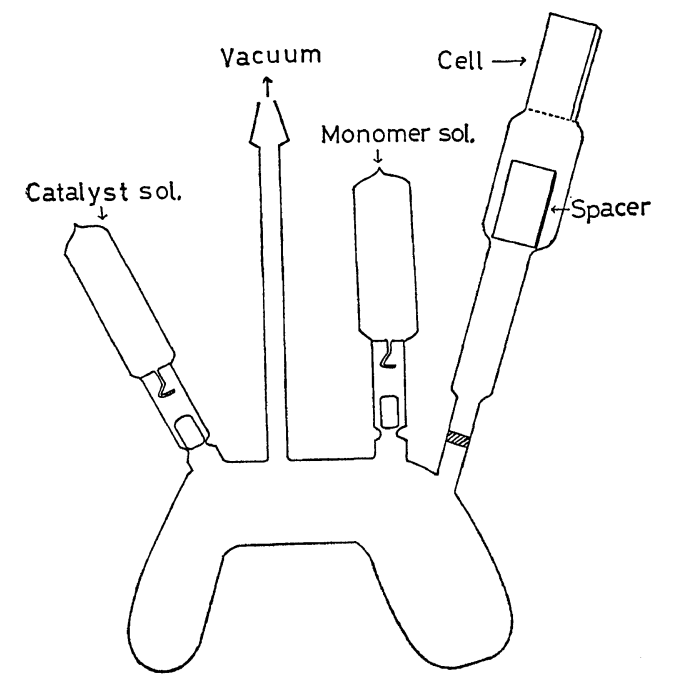

Figure 1. Apparatus equipped for initiation reaction. of $\mathrm{Ph}_{3} \mathrm{CSnCl}_{5}$, the value of $\varepsilon_{430 \mathrm{~nm}}=1.69 \times 10^{4} \mathrm{l}$ $\mathrm{mol} \mathrm{cm}$ in EDC was used. In the preceding paper it has been shown that a propagation species of 1-PB had a color in the visible range of 420 $440 \mathrm{~nm}$, but the molecular absorption coefficient $\varepsilon$ was approximately estimated as $\varepsilon=c a .10^{3}$. This means that the increase of absorbance produced by a butadienyl cation is negligible in the initial step. This was also true in the cases of the other phenylbutadiene monomers.

\section{RESULTS AND DISCUSSION}

The Rate of Initiation in Cationic Polymerization of 1-Phenylbutadiene Catalyzed by $\mathrm{Ph}_{3} \mathrm{CSnCl}_{5}$ The first-order plots of the rate of consumption

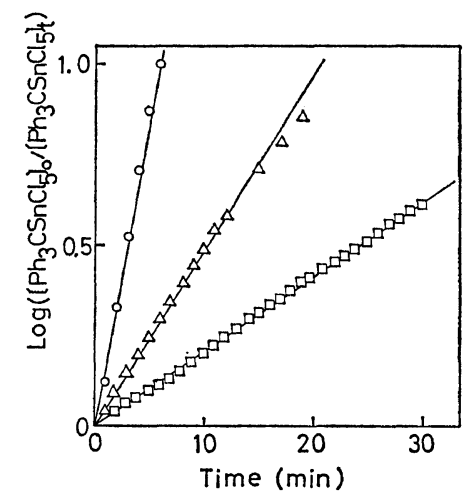

Figure 2. First-order plots for the rate of the consumption of $\mathrm{Ph}_{3} \mathrm{CSnCl}_{5}$ in the presence of 1-PB in $\mathrm{EDC}$ at $25^{\circ} \mathrm{C}:\left[\mathrm{Ph}_{3} \mathrm{CSnCl}_{5}\right]_{0}, 0.436 \mathrm{mM} ;[1-\mathrm{PB}]_{0}$, $0.070 M(\bigcirc), 0.016 M(\triangle), 0.0084 M(\square)$.

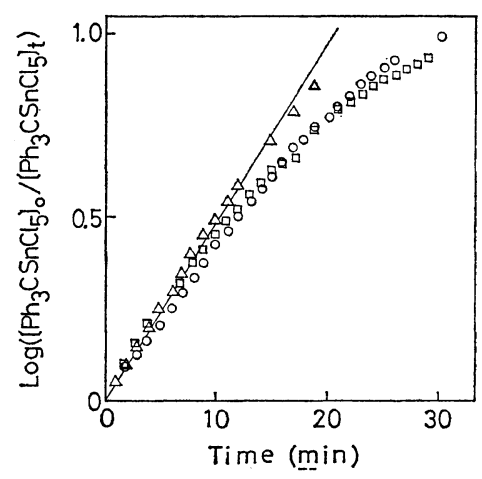

Figure 3. Effect of the concentration of $\mathrm{Ph}_{3} \mathrm{CSnCl}_{5}$ in first-order plots on the rate of the reaction of $\mathrm{Ph}_{3} \mathrm{CSnCl}_{5}$ with $1-\mathrm{PB}$ in $\mathrm{EDC}$ at $25^{\circ} \mathrm{C}$ : [1-PB], $0.016 \mathrm{M} ; \quad\left[\mathrm{Ph}_{3} \mathrm{CSnCl}_{5}\right]_{0}, 0.597 \mathrm{mM}$ (○), $0.436 \mathrm{mM}$ $(\triangle), 0.184 \mathrm{~m} M(\square)$. 
of $\mathrm{Ph}_{3} \mathrm{CSnCl}_{5}$ in an excess of 1-PB are shown in Figure 2. The slopes of the straight lines were found to be proportional to the initial concentration of 1-PB. As can be seen in Figure 3, the first-order plots of the rates of consumption of $\mathrm{Ph}_{3} \mathrm{CSnCl}_{5}$ gave one straight line regardless of the $\mathrm{Ph}_{3} \mathrm{CSnCl}_{5}$ concentration, if the 1-PB concentration was constant. Therefore, the rate of consumption can be represented as eq 1 , where $k_{\mathrm{i}}{ }^{\prime}=5.7 \mathrm{l} / \mathrm{mol} \mathrm{min}$.

$-\mathrm{d}\left[\mathrm{Ph}_{3} \mathrm{CSnCl}_{5}\right] / \mathrm{d} t=k_{\mathrm{i}}{ }^{\prime}\left[\mathrm{Ph}_{3} \mathrm{CSnCl}_{5}\right][1-\mathrm{PB}]$ (1)

This value of $k_{\mathrm{i}}{ }^{\prime}$ is about 100 times larger than that in the case of styrene. ${ }^{3}$ This fact suggests that the cinnamyl-type cation formed is much more stable than the benzyl-type cation, because of an allyl reasonance.

The Rate of Initiation in Cationic Polymerization of 2-Phenylbutadiene Catalyzed by $\mathrm{Ph}_{3} \mathrm{CSnCl}_{5}$

As shown in Figure 4, in the initiation reaction of 2-PB the absorbance of the initial concentration of $\mathrm{Ph}_{3} \mathrm{CSnCl}_{5}$, obtained by intrapolation of the time-absorbance of $\mathrm{Ph}_{3} \mathrm{CSnCl}_{5}$ at $430 \mathrm{~nm}$ to time zero, decreased to a great extent as the initial concentration of 2-PB increased. This fact suggests that the initiation scheme of 2-PB is quite different from that of 1-PB, since 1-PB concentration had no effect on

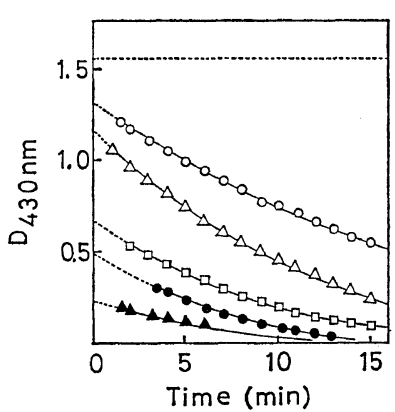

Figure 4. Initiation reaction of $\mathrm{Ph}_{3} \mathrm{CSnCl}_{5}$ with 2-PB in $\mathrm{EDC}$ at $25^{\circ} \mathrm{C}:\left[\mathrm{Ph}_{3} \mathrm{CSnCl}_{5}\right]_{0}, 0.46 \mathrm{mM}$; [2-PB] $0(--), 0.073(\bigcirc), 0.167 M(\triangle), 0.431 M$ $(\square), 0.626 M(\bullet), 1.12 M(\Delta)$.

the initial concentration of $\mathrm{Ph}_{3} \mathrm{CSnCl}_{5}$. Although it is considered that the polarity of the solution affects the dissociation of $\mathrm{Ph}_{3} \mathrm{CSnCl}_{5}$ so as to make its absorbance decrease, the large decrease of absorbance shown in Figure 4 cannot be explained only as the lowering of the polarity of the solution by the addition of monomer for as low monomer concentrations as $1 \mathrm{~mol} / \mathrm{l}$. Therefore, the authors proposed a scheme for the initiation reaction in the cationic polymerization of 2-PB catalyzed by $\mathrm{Ph}_{3} \mathrm{CSnCl}_{5}$ as follows. A remakable feature of this scheme is the coordination of monomer to catalyst.

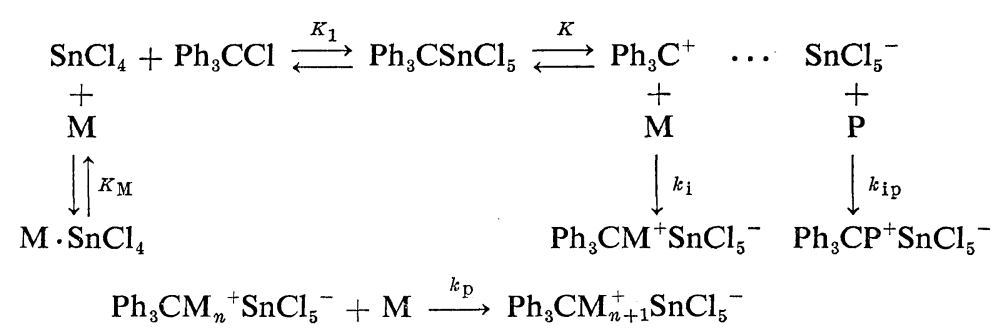

The initial concentration of $\mathrm{Ph}_{3} \mathrm{CSnCl}_{5}$ can be expressed by the following eq 2 , from the above mechanism of initiation.

$$
\begin{aligned}
& {\left[\mathrm{Ph}_{3} \mathrm{CSnCl}_{5}\right]_{0}=\left[\mathrm{Ph}_{3} \mathrm{CSnCl}_{5}\right]+\left[\mathrm{Ph}_{3} \mathrm{C}^{+} \ldots \mathrm{SnCl}_{5}{ }^{-}\right]} \\
& \quad+\left[\mathrm{SnCl}_{4}\right]+\left[\mathrm{M} \cdot \mathrm{SnCl}_{4}\right]=(1 / K)\left[\mathrm{Ph}_{3} \mathrm{C}^{+} \ldots \mathrm{SnCl}_{5}{ }^{-}\right] \\
& \quad+\left[\mathrm{Ph}_{3} \mathrm{C}^{+} \ldots \mathrm{SnCl}_{5}{ }^{-}\right]+\left[\mathrm{SnCl}_{4}\right]+K_{\mathrm{M}}[\mathrm{M}]\left[\mathrm{SnCl}_{4}\right]
\end{aligned}
$$

Therefore,

$$
\begin{aligned}
& {\left[\mathrm{Ph}_{3} \mathrm{CSnCl}_{5}\right]_{0}-(1+1 / K)\left[\mathrm{Ph}_{3} \mathrm{C}^{+} \ldots \mathrm{SnCl}_{5}^{-}\right]} \\
& \quad=\left(1+K_{\mathrm{M}}[\mathrm{M}]\right)\left[\mathrm{SnCl}_{4}\right]
\end{aligned}
$$

The relation between the initial monomer con-

centration $[2-\mathrm{PB}]_{0}$ and the value of the left side of eq 2: $\left[\mathrm{Ph}_{3} \mathrm{CSnCl}_{5}\right]_{0}-(1+1 / K)\left[\mathrm{Ph}_{3} \mathrm{C}^{+} \ldots \mathrm{SnCl}_{5}{ }^{-}\right]$, calculated from the intraporated value of $D_{430 \mathrm{~nm}}$ in Figure 4, is shown in Figure 5. Here, Higashimura, et al., estimated the value of the dissociation constant $K$ of $\mathrm{Ph}_{3} \mathrm{CSnCl}_{5}$ in EDC to be 0.84 , since $\varepsilon_{\max }$ of trityl cation was $3.7 \times$ $10^{4} \mathrm{l} / \mathrm{mol} \mathrm{cm}$ in $\mathrm{H}_{2} \mathrm{SO}_{4}{ }^{10}$ and $\varepsilon_{\max }$ of $\mathrm{Ph}_{3} \mathrm{CSnCl}_{5}$ was $1.69 \times 10^{4} \mathrm{l} / \mathrm{mol} \mathrm{cm}$ in EDC. ${ }^{3}$ If it is assumed that the concentration of $\mathrm{SnCl}_{4}$ remains constant with the increase of $[2-\mathrm{PB}]_{0}$ from 0.5 to 1.0 $\mathrm{mol} / \mathrm{l}$, the value of $K_{\mathrm{M}}$ could be calculated as 


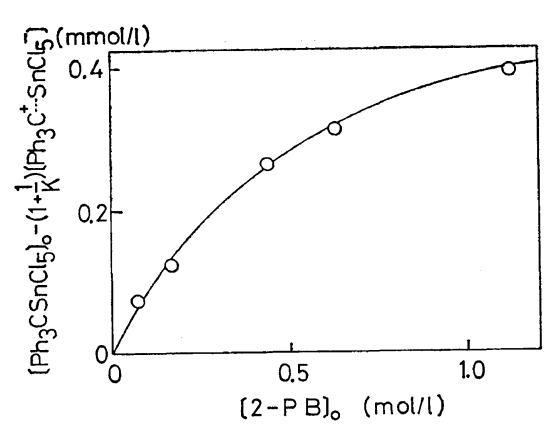

Figure 5. The relationship between the value of eq 2 and the initial concentration of 2-PB.

$K_{\mathrm{M}}=c a .4$. An explanation for the large $K_{\mathrm{M}}$, which is several times larger than $K$, is that 2-PB easily form a cisoid conformation, then cis bidentate occupies two coordination sites of $\mathrm{SnCl}_{4}$ by means of a $\pi$-electron as follows<smiles>[Se]C1CC2CC(c3ccccc3)(C1)C2</smiles>

The initiation of 2-PB by $\mathrm{Ph}_{3} \mathrm{CSnCl}_{5}$ was performed at monomer concentrations as low as $10^{-2} \mathrm{~mol} / l$ to minimize the effect of a coordination between 2-PB and $\mathrm{SnCl}_{4}$. The first-order plots of the rate of consumption of $\mathrm{Ph}_{3} \mathrm{CSnCl}_{5}$ in the presence of 2-PB are given in Figure 6. The concave curve shown in Figure 6 means

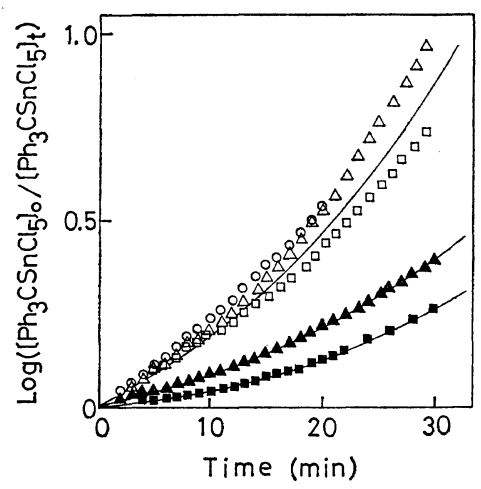

Figure 6. First-order plots for the rate of the reaction of $\mathrm{Ph}_{3} \mathrm{CSnCl}_{5}$ with 2-PB in $\mathrm{EDC}$ at $25^{\circ} \mathrm{C}$ : $\left[\mathrm{Ph}_{3} \mathrm{CSnCl}_{5}\right]_{0}, 0.39 \mathrm{mM}$; [2-PB $]_{0}, 0.073 M(\triangle), 0.036$ $M(\Delta), 0.019 M(\square):[2-\mathrm{PB}]_{0}, 0.073 M ;\left[\mathrm{Ph}_{3} \mathrm{CSnCl}_{5}\right]_{0}$, $0.60 \mathrm{~m} M(\bigcirc), 0.39 \mathrm{~m} M(\triangle), 0.18 \mathrm{~m} M(\square)$. an acceleration of the reaction at high conversion. Since 2-PB was found to polymerize rather rapidly by Friedel-Crafts catalyst, it is suggested that this accelerated consumption of $\mathrm{Ph}_{3} \mathrm{CSnCl}_{5}$ was caused by the reaction of $\mathrm{Ph}_{3} \mathrm{CSnCl}_{5}$ with active double bonds of the polymer produced. This assumption was demonstrated by the fact that $\mathrm{Ph}_{3} \mathrm{CSnCl}_{5}$ reacted with poly(2-PB), but the rate was not determined. The results obtained in Figure 6 show that the initial rate of consumption of $\mathrm{Ph}_{3} \mathrm{CSnCl}_{5}$ was proportional to both the initial concentration of the monomer and that of $\mathrm{Ph}_{3} \mathrm{CSnCl}_{5}$. Therefore, the total rate of consumption of $\mathrm{Ph}_{3} \mathrm{CSnCl}_{5}$ was well represented by the following equation

$$
\begin{aligned}
& -\mathrm{d}\left[\mathrm{Ph}_{3} \mathrm{CSnCl}_{5}\right] / \mathrm{d} t=k_{\mathrm{i}}{ }^{\prime}\left[\mathrm{Ph}_{3} \mathrm{CSnCl}_{5}\right][\mathrm{M}] \\
& +k_{\mathrm{i}}{ }^{\prime \prime}\left[\mathrm{Ph}_{3} \mathrm{CSnCl}_{5}\right]\left([\mathrm{M}]_{0}-[\mathrm{M}]\right)
\end{aligned}
$$

where $k_{\mathrm{i}}{ }^{\prime}\left(25^{\circ} \mathrm{C}\right)$ was found to be $0.67 \mathrm{l} / \mathrm{mol} \mathrm{min}$.

The Rate of Initiation in Cationic Polymerization of Diphenylbutadienes by $\mathrm{Ph}_{3} \mathrm{CSnCl}_{5}$

In preceding sections, the behavior of 1-PB in the reaction with $\mathrm{Ph}_{3} \mathrm{CSnCl}_{5}$ has been shown to be quite different from that of 2-PB. Because of the steric hindrance of the bulky phenyl group, a trans conformation is favorable to 1-PB, while in the case of 2-PB a cisoid conformation is predominant, as shown in the case of 2-t-butyl-1,3butadiene. $^{11}$ Therefore, to obtain more information about the steric effect of the phenyl group,

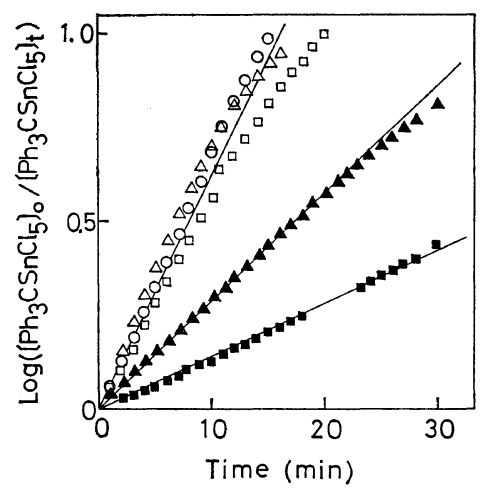

Figure 7. First-order plots for the rate of the reaction of $\mathrm{Ph}_{3} \mathrm{CSnCl}_{5}$ with 1,1-DPB in $\mathrm{EDC}$ at $25^{\circ} \mathrm{C}$ : $\left[\mathrm{Ph}_{3} \mathrm{CSnCl}_{5}\right]_{0}, 0.34 \mathrm{~m} M ; \quad[1,1-\mathrm{DPB}]_{0}, 0.24 M(\bigcirc)$, $0.12 M(\Delta), \quad 0.068 M(\mathbb{G}): \quad[1,1-\mathrm{DPB}]_{0}, \quad 0.24 M$; $\left[\mathrm{Ph}_{3} \mathrm{CSnCl}_{5}\right]_{0}, 0.47 \mathrm{~m} M(\triangle), 0.34 \mathrm{~m} M(\bigcirc), 0.18 \mathrm{~m} M$ (口). 
Cationic Polymerization of Phenylbutadienes. II.

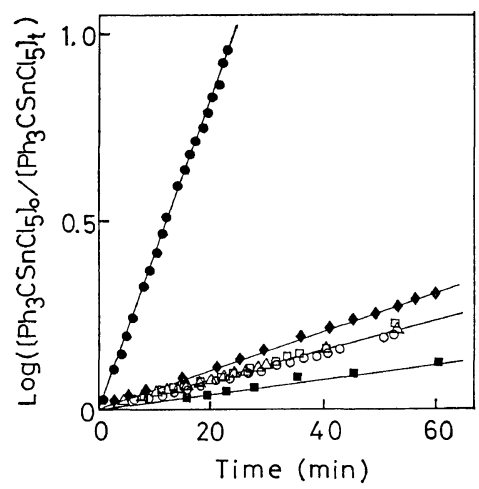

Figure 8. First-order plots for the rate of the reaction of $\mathrm{Ph}_{3} \mathrm{CSnCl}_{5}$ with 1,2-DPB in EDC at $25^{\circ} \mathrm{C}:\left[\mathrm{Ph}_{3} \mathrm{CSnCl}_{5}\right]_{0}, 0.32 \mathrm{mM}$; [1,2-DPB $]_{0}, 0.184 M$ (๑), $0.060 M(\triangleleft), 0.033 M(\triangle), 0.017 M(\triangle)$ : [1,2$\mathrm{DPB}]_{0}, 0.033 M ;\left[\mathrm{Ph}_{3} \mathrm{CSnCl}_{5}\right]_{0}, 0.64 \mathrm{~m} M(\bigcirc), 0.32$ $\mathrm{m} M(\triangle), 0.14 \mathrm{~m} M(\square)$.

the reaction of isomers of diphenylbutadiene with $\mathrm{Ph}_{3} \mathrm{CSnCl}_{5}$ was performed.

The pseudo-first-order plots of the rate of consumption of $\mathrm{Ph}_{3} \mathrm{CSnCl}_{5}$ with 1,1-DPB and 1,2DPB are shown in Figures 7 and 8, respectively. The rates of initiation of 1,1-DPB and 1,2-DPB could be expressed as a second-order reaction which is proportional to both the initial concentration of the monomer and that of $\mathrm{Ph}_{3} \mathrm{CSnCl}_{5}$, as was found in the case of 1-PB. The bimolecular initiation reaction rate constants, $k_{\mathrm{i}}{ }^{\prime}$ were obtained as follows

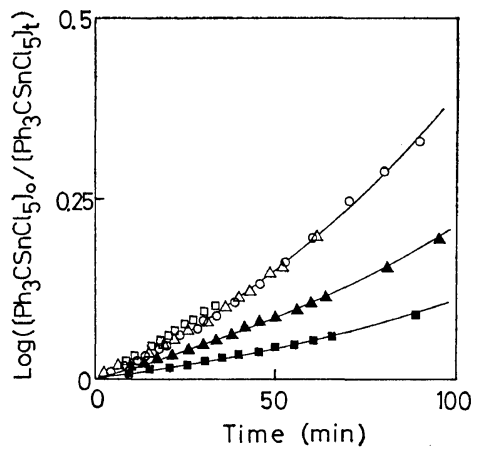

Figure 9. First-order plots for the rate of the reaction of $\mathrm{Ph}_{3} \mathrm{CSnCl}_{5}$ with 2,3-DPB in EDC at $25^{\circ} \mathrm{C}$ : $\left[\mathrm{Ph}_{3} \mathrm{CSnCl}_{5}\right]_{0}, 0.39 \mathrm{mM} ; \quad[2,3-\mathrm{DPB}]_{0}, 0.34 M(\bigcirc)$, $0.18 M(\boldsymbol{\Delta}), \quad 0.12 M(\square) ; \quad[2,3-\mathrm{DPB}]_{0}, \quad 0.34 M$; $\left[\mathrm{Ph}_{3} \mathrm{CSnCl}_{5}\right]_{0}, 0.55 \mathrm{mM}(\triangle), 0.39 \mathrm{~m} M(\bigcirc), 0.16 \mathrm{mM}$ (口).

$$
\begin{aligned}
& k^{\prime}\left(25^{\circ} \mathrm{C}\right)=0.49 \mathrm{l} / \mathrm{mol} \mathrm{min} \text { for } 1,1-\mathrm{DPB} \\
& k^{\prime}\left(25^{\circ} \mathrm{C}\right)=0.32 \mathrm{l} / \mathrm{mol} \mathrm{min} \text { for } 1,2-\mathrm{DPB}
\end{aligned}
$$

The first-order plots of consumption of $\mathrm{Ph}_{3}$ $\mathrm{CSnCl}_{5}$ with 2,3-DPB are shown in Figure 9. The rate was much slower than those of 1,1-DPB and 1,2-DPB, and an acceleration of the reaction was observed. This acceleration seems to be ascribed to the reaction of $\mathrm{Ph}_{3} \mathrm{CSnCl}_{5}$ with the polymer produced, as was suggested in the case of 2-PB. Hence the rate could be represented by eq 3 , where the rate constant was calculated.

$k^{\prime}\left(25^{\circ} \mathrm{C}\right)=0.023 \mathrm{l} / \mathrm{mol} \mathrm{min}$ for 2,3-DPB

In the case of 1,4-DPB, the reaction with $\mathrm{Ph}_{3} \mathrm{CSnCl}_{5}$ was followed for several hours at $55^{\circ} \mathrm{C}$, but no consumption of $\mathrm{Ph}_{3} \mathrm{CSnCl}_{5}$ was observed. It is sure that $1,4-\mathrm{DPB}$ is very stable against electrophilic reagents such as FriedelCrafts catalysts.

In the cases of diphenylbutadienes, the polymerized solution was poured into a large excess of methanol, but no polymer insoluble in methanol was obtained.

The Reactivity of Phenylbutadienes to $\mathrm{Ph}_{3} \mathrm{CSnCl}_{5}$

From the above results, the reactivity of phenyl-substituted butadienes to $\mathrm{Ph}_{3} \mathrm{CSnCl}_{5}$ was shown to decrease according to the following order

$$
\begin{aligned}
1-\mathrm{PB} & >2-\mathrm{PB}>1,1-\mathrm{DPB}>1,2-\mathrm{DPB} \\
& >2,3-\mathrm{DPB}>1,4-\mathrm{DPB}
\end{aligned}
$$

This order seems to be consistent with that of the stability of the phenyl-substituted allyl carbonium ions formed.

The rates of initiation of phenylbutadienes were also measured over the range of temperatures from 5 up to $55^{\circ} \mathrm{C}$. The values of $k_{\mathrm{i}}$, activation enthalpy, and activation entropy are summarized in Table I. Figure 10 shows plots of $\log k_{\mathrm{i}}$ against $1 / T$.

From the results described above, the phenylbutadienes seem to be classified into two categories. The first group includes 1-position substituted butadienes, i.e., 1-PB, 1,1-DPB, and 1,2-DPB, and the second group includes 2-position substituted ones, i.e., 2-PB and 2,3-DPB. For the 1st group monomers the rate of consumption of $\mathrm{Ph}_{3} \mathrm{CSnCl}_{5}$ could be presented by a 2 nd-order reaction such as eq 1 , whereas in the second group, the $\pi$-complex formation between mono- 


\section{R. Asami and K. Hasegawa}

Table I. Initiation rate constants and activation parameters for the reaction of $\mathrm{Ph}_{3} \mathrm{CSnCl}_{5}$ with phenylbutadienes in $\mathrm{EDC}^{\mathrm{a}}$

\begin{tabular}{|c|c|c|c|c|}
\hline $\begin{array}{l}\text { Phenyl- } \\
\text { butadiene }\end{array}$ & $\underset{{ }^{\circ} \mathrm{C}}{\text { Temp, }}$ & $\begin{array}{c}k_{\mathrm{j}}, \stackrel{\mathrm{b}}{l} \\
l / \mathrm{mol} \min \end{array}$ & $\begin{array}{c}\Delta H^{\neq} \\
\mathrm{kcal} / \mathrm{mol}\end{array}$ & $\begin{array}{c}\Delta S^{\neq} \\
\mathrm{cal} / \mathrm{deg}\end{array}$ \\
\hline \multirow[t]{4}{*}{ 1-PB } & 5.0 & 2.74 & \multirow{4}{*}{9.8} & \multirow{4}{*}{-15.1} \\
\hline & 25.0 & 12.5 & & \\
\hline & 35.0 & 27.5 & & \\
\hline & 55.0 & 45.1 & & \\
\hline \multirow[t]{4}{*}{ 1,1-DPB } & 10.0 & 0.424 & \multirow{4}{*}{9.3} & \multirow{4}{*}{-19.3} \\
\hline & 25.0 & 1.10 & & \\
\hline & 35.0 & 1.90 & & \\
\hline & 55.0 & 4.79 & & \\
\hline \multirow[t]{4}{*}{ 1,2-DPB } & 10.0 & 0.184 & \multirow{4}{*}{13.6} & \multirow{4}{*}{-7.9} \\
\hline & 25.0 & 0.760 & & \\
\hline & 35.0 & 2.51 & & \\
\hline & 55.0 & 5.36 & & \\
\hline \multirow[t]{4}{*}{$2-P B$} & 5.0 & 0.449 & \multirow{4}{*}{8.5} & \multirow{4}{*}{-23.9} \\
\hline & 25.0 & 1.35 & & \\
\hline & 35.0 & 2.67 & & \\
\hline & 55.0 & 5.21 & & \\
\hline \multirow[t]{4}{*}{ 2,3-DPB } & 10.0 & 0.0204 & \multirow{4}{*}{9.9} & \multirow{4}{*}{-25.6} \\
\hline & 25.0 & 0.0515 & & \\
\hline & 35.0 & 0.114 & & \\
\hline & 55.0 & 0.251 & & \\
\hline
\end{tabular}

a Activation parameters were calculated from $k_{\mathrm{i}}$ by the least-squares method.

is $k_{\mathrm{i}}=k_{\mathrm{i}}{ }^{\prime}(K+1) / K$.

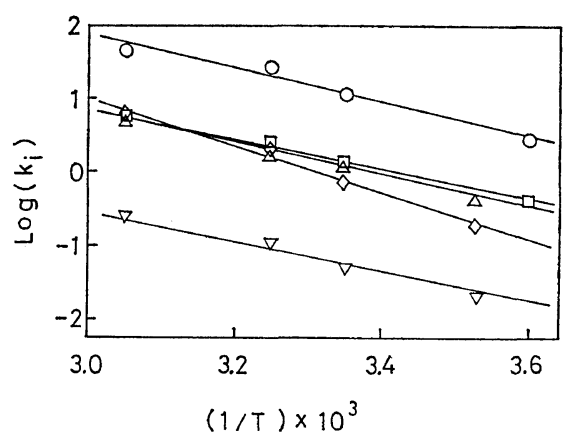

Figure 10. Arrhenius plots of the initiation rate constant for the reaction of $\mathrm{Ph}_{3} \mathrm{CSnCl}_{5}$ with phenylbutadienes in EDC: $\bigcirc, 1-\mathrm{PB} ; \triangle, 1,1-\mathrm{DPB} ; \diamond$, 1,2-DPB; $\square, 2-\mathrm{PB} ; \nabla, 2,3-\mathrm{DPB}$.

mer and $\mathrm{SnCl}_{4}$ competes with the initiation of monomer by $\mathrm{Ph}_{3} \mathrm{CSnCl}_{5}$, especially in the case of 2-PB at high concentration. The rate of consumption of $\mathrm{Ph}_{3} \mathrm{CSnCl}_{5}$ determined at low monomer concentrations could be represented by eq 3 . The case of $\pi$-complex formation of the 2nd group's monomers would be ascribed to their preferable cisoid conformation. One of us already has found that 2,3-DPB could easily make a five-membered ring complex with metal Mg. ${ }^{12}$ This fact will support a $\pi$-complex between 2-PB and $\mathrm{SnCl}_{4}$ in the fashion of a cis conformation. It can be seen in Table $I$ that the activation enthalpies for the 1st group's monomers are as high as or a little higher than those of the 2 nd group, but the activation entropies of the latter are much lower than the former's. The low activation entropy of 2-PB and 2,3-DPB could be ascribed to a $\pi$-complex formation with a carbonium ion in the transition state. The same value of activation entropy has been reported for the cases of styrene and $\alpha$-methylstyrene $^{3}$ and a cyclic carbonium-ion intermediate has been proposed at the transition state. ${ }^{13}$ The trityl cation, $\mathrm{Ph}_{3} \mathrm{C}^{+}$, attacks the 4-position carbons of the 1st group's monomer and the 1-position of the 2nd group's one, forming similar allyl cation, as shown in the cases of 1-PB and 2-PB.

$$
\begin{gathered}
\mathrm{PhCH}=\mathrm{CH}-\mathrm{CH}=\mathrm{CH}_{2}+\mathrm{Ph}_{3} \mathrm{C} \oplus \rightarrow \\
\mathrm{PhCH}-\mathrm{CH}-\mathrm{CH}-\mathrm{CH}_{2}-\mathrm{CPh}_{3} \\
\mathrm{CH}_{2}=\mathrm{CPh}-\mathrm{CH}=\mathrm{CH}_{2}+\mathrm{Ph}_{3} \mathrm{C} \oplus \rightarrow \\
\mathrm{Ph}_{3} \mathrm{C}-\mathrm{CH}_{2}-\mathrm{CPh} \underset{\oplus}{\mathrm{CH}}-\mathrm{CH}_{2}
\end{gathered}
$$

A similar stabilization of both carbonium ions seems to be responsible for the same activation enthalpy of both monomers. The slow rates for the cases of 2,3-DPB and 1,2-DPB might be explained interms of the less stable carbonium ion, due to cross conjugation.

Discussion of the transition state for cationic polymerization of phenylbutadienes will be given in detail in the following paper on copolymerization. ${ }^{14}$

\section{REFERENCES}

1. R. Asami, K. Hasegawa, and T. Onoe, Polymer J., 8, 43 (1976).

2. T. Saegusa and S. Matsumoto, J. Polym. Sci., Part $A-1,6,1559$ (1968), and the subsequent papers.

3. T. Higashimura, T. Fukushima, and S. Okamura, J. Macromol. Chem., 1, 683 (1967).

4. M. S. Sambhi, Macromolecules, 3, 351 (1970). 
Cationic Polymerization of Phenylbutadienes. II.

5. C. S. Marvel and R. G. Woolfold, J. Org. Chem., 23, 1658 (1958).

6. J. J. Eisch and G. R. Husk, ibid., 31, 589 (1966).

7. K. Alder, J. Haydn, K. Heimbach, K. Neufang, G. Hansen, and W. Gerhard, Ann., 586, 110 (1954).

8. B. B. Corson in "Organic Syntheses," Coll. II, John Wiley \& Sons, Inc., New York, N.Y., p 77.

9. C. F. H. Allen, C. G. Eliot, and A. Bell, Can.
J. Res., 17B, 75 (1939).

10. A. Bentley, A. G. Evans, and J. Halpern, Trans. Faraday Soc., 47, 711 (1951).

11. R. T. Hobgood and J. H. Goldstein, J. Mol. Spectrosc., 12, 76 (1964).

12. R. Asami and Y. Kondo, to be published.

13. T. Okuyama, N. Asami, and T. Fueno, Bull. Chem. Soc. Japan, 43, 3553 (1970).

14. R. Asami, K. Hasegawa, N. Asai, I. Moribe, and A. Doi, Polymer J., 8, 74 (1976). 